\title{
Traducción
}

\section{Radical y feminista: africana de otra manera ${ }^{12}$}

\author{
Being Radical and Feminist: Belonging to Africa in New Ways
}

Patricia McFadden

\section{Introducción por Mónica Cejas}

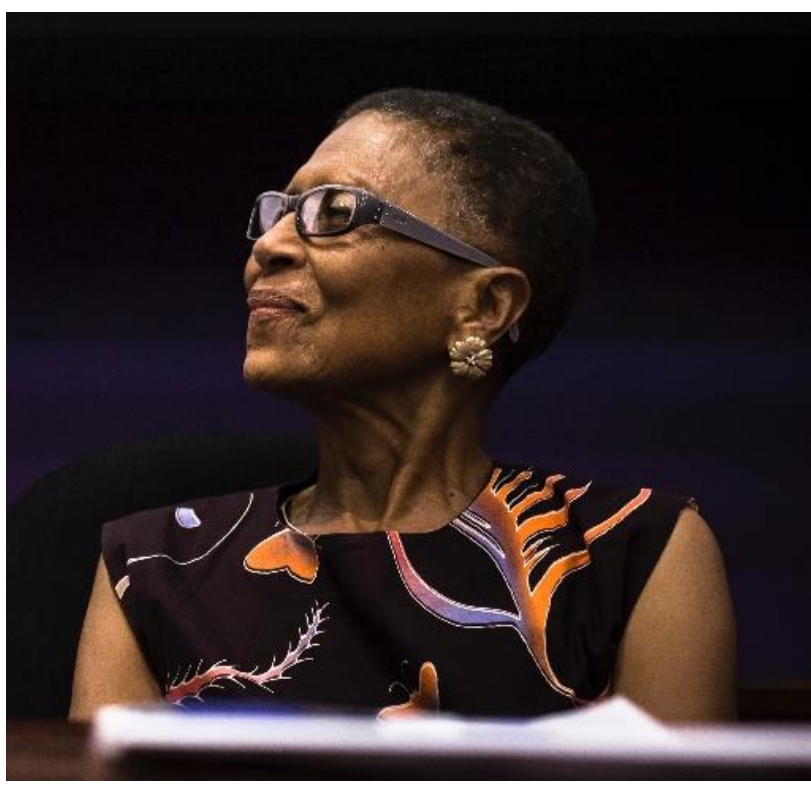

Patricia McFadden presidiendo el panel Histories of Embodied Entanglements el 5 de septiembre de 2019 en la Universidad de Witwatersrand (Johannesburgo, Sudáfrica). Imagen:

https://fr.wikipedia.org/wiki/Patricia_McFadden\#/media/ Fichier:Afems2019 HistoriesOfEmbodiedEntanglements 0 11.jpg
Patricia McFadden es una feminista radical, socióloga, escritora y educadora africana nacida en Eswatini (Suazilandia), con un activo feminismo en el continente y fuera de él. Fue directora del prometedor Centro de Estudios Feministas de Harare, Zimbabue fundado en 1995 y editora de la revista SAFERE (Southen African Feminist Review) que alimentaba un intenso debate entre feministas de la región. Ambos espacios, sufrieron los embates de un gobierno que promovía un proyecto nacionalista patriarcal y androcéntrico donde la palabra feminista no podía, por definición, encontrar cabida. El primero de ellos fue cerrado argumentando problemas en su registro, y la publicación, después

\footnotetext{
1 Conferencia magistral -23 de noviembre de 2019- organizada por la Asamblea de Mujeres de la Asociación estadounidense de estudios de africanos (African Studies Association) en el marco de la conferencia anual de 2019 celebrada en Boston del 21 al 23 de noviembre. Véase: https://africanstudies.org/wp-content/uploads/2017/08/2019PreliminaryProgram.pdf

${ }^{2}$ Introducción y traducción a cargo de Mónica Inés Cejas.
}

Esta obra está sujeta a la Licencia Reconocimiento-NoComercial-CompartirIgual 4.0 Internacional de Creative Commons. http://creativecommons.org/licenses/by-nc-sa/4.0/ 


\section{Patricia McFadden}

de cuatro exitosas ediciones en 1995 y 1996, se quedó sin recursos. McFadden, con sus incisivas reflexiones desde un feminismo radical, que abreva en el mismo pensamiento africano en diálogo con el feminismo afroestadounidense y sus propias experiencias como mujer negra africana académica y activista, ha producido y produce un pensamiento propio sobre las diversas manifestaciones del feminismo en el continente, sobre sus alcances y limitaciones.

Actualmente vive en su país de nacimiento, allí cultiva su propio alimento trabajando el campo por las mañanas y escribiendo sus agudas reflexiones por las tardes. La visité en junio de 2019 y durante diez días conviví con ella acompañando su cotidianeidad. Fue un tiempo compartido de diálogo y escucha junto al trabajo en el campo y la elaboración y goce de alimentos, de bellos atardeceres desde la cima de la antigua montaña donde está su hogar cerca de Siteki. Diez días de intensivo aprendizaje sobre un feminismo que hunde sus raíces en la lucha anti colonial (anti apartheid en la región), en una visión panafricana de la historia que incluye la diáspora, y donde lo personal que es político abraza al vínculo con la naturaleza como economía política de vida y a la sanación como un saber revolucionario de las mujeres en comunidad.

A continuación, y con la autorización de Patricia, presentamos la traducción de su conferencia magistral en la 62th Conferencia anual de la Asociación Estadounidense de Estudios Africanos (The African Studies Association, ASA por sus siglas en inglés) con el tema: "Ser, pertenecer y devenir en África" (Being, belonging and becoming in Africa). Cabe destacar que el título de su conferencia "Radical y feminista: africana de otra manera", es en sí una declaración al respecto.

\section{Radical y feminista: africana de otra manera}

Cuando Maha $^{3}$ y sus colegas me invitaron a compartir estos momentos con ustedes hoy, me sentí favorecida por el privilegio y la alegría de que comunicar mi pensamiento en comunidad, me permitiría ser parte de ustedes. Toda mi vida feminista -y hace medio siglo que di el primer paso para ser una mujer radicalpensar, resistir y celebrar con mis hermanas ha sido una fuente muy importante de fortaleza y felicidad para mí.

La comunidad feminista no siempre ha sido el lugar más seguro, dado lo porosos que son sus límites y las vulnerabilidades de los esencialismos que a menudo nos dejan desnudas ante intrigas y luchas por el poder -malos hábitos que hemos aprendido durante milenios de proximidad al patriarcado. No obstante, como el pequeño pájaro que intencional y decididamente construye su nido ante una tormenta que se avecina y lo termina antes de que el trueno golpee los cielos, yo

\footnotetext{
${ }^{3}$ Se refiere a Maha Marouan, académica de origen marroquí, actualmente profesora de estudios de Mujeres, género y sexualidades de la Universidad de Pensilvania, Estados Unidos, quien en 2019 fue una de las coordinadoras del encuentro anual de la Asociación estadounidense de estudios africanos (ASA).
} 
también he llegado a saber que la colectiva es mi hogar, mi lugar de pertenencia donde encuentro amor, intuiciones, sabiduría y amistad con mis hermanas en la lucha por recuperar nuestra Libertad. Por eso, gracias.

Elaboré el título de mi presentación como una oportunidad que está en consonancia con el tema más amplio de la conferencia de la ASA de este año ${ }^{4}$, sin que quede eclipsado por los supuestos masculinistas y patriarcales subyacentes que infunden las nociones clave de ser, pertenecer y devenir en relación con África.

No he escuchado mucho feminismo o discurso feminista desde que llegué aquí, a pesar de encontrarme con muchas mujeres, predominantemente negras, en los pasillos y salas de conferencia. Algunas de nosotras probablemente nos estemos haciendo esta pregunta: $i$ se ha convertido la Asamblea de mujeres de la ASA en un lugar de refugio y exclusión para las mujeres, de modo que los hombres respiren aliviados de que podamos "desahogarnos" en este pequeño espacio guetoizado, mientras ellos continúan dominando los problemas académicos reales de la erudición africana? Desde donde estoy posicionada como una forastera viendo hacia adentro (ya no trafico en la academia), los hombres parecen tener un lenguaje corporal relajado que indica un sentido de propiedad y comodidad con el status quo, pose similar a la de los hombres blancos que dominaron esta Asociación durante décadas, cediendo terreno de mala gana a los hombres negros después de muchas y agotadoras batallas por la propiedad de África en sus infinitas sensibilidades.

¿Cuáles son entonces las implicaciones de no hablar de nuestro feminismo en los espacios centrales de la ASA? ¿No deberíamos preguntarnos, como mujeres que conocen las verdaderas realidades de la vida en el terreno existencial africano y plenamente conscientes de la urgencia de crear nuevas formas de vida y de vivir, cuánto tiempo seremos la audiencia de los hombres? ¿De discursos parlanchines y a menudo profundamente reaccionarios y conservadores que reiteran el status quo en todos los lugares donde los africanos viven y luchan? Espero que tomemos en consideración esta cuestión y la mencionemos en nuestras conversaciones.

Mi intención deliberada de estar aquí, es cambiar la aguja en dirección a una energía feminista que hará que los largos viajes que hemos hecho para llegar a este lugar valgan la pena.

Entonces, hablaré sobre "Ser", "Radical", "Feminista" y "Pertenencia” como mujeres que buscamos la libertad en términos de la revisión y redefinición de nosotras mismas, nuestras identidades políticas y personales y el trabajo revolucionario necesario en el que estamos comprometidas como feministas cualquiera sea el lugar en que nos ubiquemos. Sea cual sea el trabajo feminista que estemos haciendo, cómo y dónde nos comprometemos con él y en él, debemos entender que somos parte de una revolución. Este es un imperativo contemporáneo que debe cumplirse para

\footnotetext{
${ }^{4}$ Como se señaló en la introducción, se trató de la 62th Conferencia anual de la Asociación estadounidense de estudios africanos (ASA por sus siglas en inglés) con el tema: "Ser, pertenecer y devenir en África" (Being, belonging and becoming in Africa).
} 


\section{Patricia McFadden}

responder de manera eficaz a la catastrófica implosión que está arruinando nuestras vidas en todo el planeta.

El feminismo es un proceso revolucionario. Es un trabajo político serio. No puede tomarse como una moda o una tendencia. Requiere de coraje y la continua adquisición de conocimientos sobre las maneras en que las mujeres han resistido al patriarcado desde sus inicios en el momento de la creación del excedente. Existe un extenso tesoro escrito, hablado, documentado, actuado, pintado, cantado y vivido por el feminismo del que toda mujer radical puede y debe apropiarse para comprender la enormidad y el valor de ser radical y feminista.

Para mí, el feminismo ha sido un viaje a menudo asombrosamente difícil y estimulante del que no se puede volver al conservadurismo y al atraso de la sumisión y deferencia patriarcal; es un viaje de autodescubrimiento y el aprendizaje de amar aquello de mí que desconocía, aunque me constituye. Como dijo Audre Lorde de ella misma: "Todavía estoy aprendiendo: cómo alegrarme de todas las personas que soy, cómo usar todo mi ser al servicio de lo que creo, cómo aceptar cuando fallo y regocijarme cuando tengo éxito". Y es que cuando nos atrevemos a ser libres y hacemos realidad la sensación de ser libres, nos conectamos con quienes nos rodean.

Ayer, cuando fui a registrarme, le pedí a la mujer a cargo que me identificara -en la tarjeta de identificación que portaría durante el congreso- como "Feminista Autónoma". Ella se sorprendió, porque el status quo se establece en el mismo acto de decir quién eres en la referencia [generalmente institucional] que usas para los días de la conferencia. El supuesto es que debes ser "ubicada" en una institución de cuyo nombre se extrae "tu identidad". Perteneces a ese sitio de gestión y definición académica. Te da la licencia para estar aquí, y la mayoría de nosotras simplemente aceptamos el borrado estructural como parte de la supervivencia diaria en este lugar de gran desolación, especialmente como africanas. Después de una breve conversación sobre por qué elegí ser identificada como autónoma y feminista, ella dijo tímidamente que le encantaba la idea, y salí del mostrador con la sensación de satisfacción de que podría haber abierto una ventana a través de la cual ella podía vislumbrar nuevas posibilidades para ella misma.

Ésta y una miríada de otras razones hacen que denominarnos feministas de la manera más radical, sea esencial para la tarea de liberarnos de los hábitos y restricciones de la sociedad patriarcal, para que podamos imaginar nuevos mundos y realidades alternativas al caos y fracaso del patriarcado como son el capitalismo, el racismo, la homofobia, el odio, el militarismo, la supremacía y todas las exclusiones y negaciones que caracterizan al milenio pasado y más allá en el tiempo.

\section{Ser consciente y ser humano: ser completo}

Permítanme comenzar con el Ser. Después de todo es la realidad de la que todos emergemos, en los ritmos naturales del universo. En la naturaleza, el ser está determinado por las dimensiones aparentemente ocultas y a menudo insondables 


\section{Radical y feminista: africana de otra manera}

de la vida, el vivir y la muerte. Como humanos, debemos haber comenzado a recorrer el planeta asombrados por las innumerables especies que habitaban todos los sitios que hacen de éste, un lugar asombroso, lleno de vida. Probablemente estábamos tan deslumbrados por su inmensidad que caminamos con cautela entre los que vinieron antes que nosotros: los seres sensibles que luego se convirtieron en cosas para ser cazadas, masacradas, torturadas, aterrorizadas, encarceladas, pesadas, vendidas y desechadas. Su destrucción y extinción en muchos casos todavía se justifica a través de los mitos de la creación supremacista y las mentiras de la providencia divina, vinculadas a la mercantilización capitalista y la obtención de ganancias, que continúan haciendo que el genocidio de la mayoría de los demás seres vivos sea "normal".

Muchos de nosotros nos consideramos civilizados por consumir sus cuerpos todos los días, como parte del desempeño de nuestro logro superior como humanos. Durante la primera mitad de mis 67 años, participé en la domesticación, matanza, preparación y disfrute de cuerpos sensibles. Mis padres acumularon una gran riqueza como propietarios de carnicerías, y la carne era una clara declaración social de que nuestra familia lo había logrado -un mayor estatus-, en términos de clase.

Convertirme en vegana inició uno de los cambios más poderosos de mi vida, permitiéndome recuperar mi sensibilidad, la capacidad de sentir, percibir y experimentar la subjetividad, elementos que son fundamentales para la conciencia y la agencia feministas. Fue entonces cuando me di cuenta de cuán inmensa se ha vuelto la brecha entre nosotros, los humanos, que tratamos a otras criaturas vivientes y plantas como cosas sin sentimientos ni conciencia, y la vida. Permítanme repetir este mensaje porque es tan fundamental para la conciencia revolucionaria que debemos adquirir y cultivar para sobrevivir y prosperar como mujeres y como participantes en un proyecto humanista alternativo:

\footnotetext{
"Un ser sensible, que incluye a los humanos, puede sentir, percibir y sentir cosas. Tiene conciencia del entorno, las sensaciones, los pensamientos y la capacidad de mostrar capacidad de respuesta. Tener sentido hace que algo sea sensible o capaz de oler, comunicarse, tocar, ver u oír. Todos los seres sensibles tienen conciencia de sí mismos. Pueden sentir felicidad, tristeza, dolor y miedo" (From Nature's Heart)
}

¿Con qué frecuencia en los últimos tres años se ha escuchado a alguien expresar su horror al darse cuenta de que el régimen en el poder "no siente empatía por otros seres humanos" y que Trump es insensible a cualquier emoción humana (aparte de sentir rabia y desprecio por la mayoría de la gente)? Cuando la llamada crisis de los inmigrantes estaba en su apogeo, la gente se preguntaba: ¿cómo pueden hacer esto?, poner a los niños en jaulas, arrebatar bebés de los brazos de madres aterrorizadas, dispersar a los niños a lo largo y ancho de este país, perdidos para siempre en muchos casos, para sus padres y familias; construir y extender muros a lo largo de la frontera sur de este país, presumiblemente para "mantener fuera a las personas morenas infestadas de enfermedades", porque no pertenecen a un espacio 


\section{Patricia McFadden}

que ha sido marcado como "blanco y masculino", un espacio robado, ecológica y socialmente devastado, donde los nativos permanecen escondidos a plena vista. ¡La asombrosa arrogancia del patriarcado capitalista blanco!

Estas preguntas son profundas y necesarias porque esta sociedad ha llegado a su punto más bajo. De aquí en adelante sin un cambio hacia otra dirección basada en el ser humano, el capitalismo la conducirá al precipicio. Esto es inevitable para esta sociedad y para cualquier otro lugar que haya colocado a las ganancias en el centro de su existencia. Alguien me susurró con complicidad que debería ser cautelosa con la forma en que hablo mientras estoy aquí porque... y les pregunté: "entonces, ¿qué significan para ustedes la democracia y la libertad de expresión? El silencio no te protegerá"... y ser radical implica la valentía de decirle la verdad al poder.

Como alguien que honra la vida vegana, con frecuencia me hacen esta molesta pregunta: entonces, ¿qué comes? ¿Por dónde empezar a responder una pregunta tan ridículamente ignorante? ¿Es posible que tantos humanos hayan olvidado la inmensa generosidad de la abundancia de plantas y frutas de la naturaleza y el significado de la comida como alimento y placer en lugar de como una expresión de privilegio de clase o despojo?

En mi búsqueda de plenitud, de un feminismo que me permitiera prosperar y continuar creciendo como una mujer mayor que ha tomado conciencia de su capacidad para conectarse con otras mediante las antiguas tradiciones de sanación, supe que la conexión entre mujeres y el poder de las energías naturales había sido declarado desdeñosamente como un signo de inferioridad e irracionalidad.

Por lo tanto, en la tradición radical de una mujer inconforme, me propuse recuperar y restablecer mi relación con los demás seres y con la tierra, elaborando un estilo de vida alternativo basado en el respeto de todas las formas de vida (irritantes o placenteras). Pronto me di cuenta de que aquellos seres que habían sobrevivido al ataque humano en las tierras donde vivo y trabajo, lo habían hecho en gran parte gracias a un asombroso sentido de resiliencia y a un sentido extremadamente elevado de vigilancia y desconfianza hacia los humanos. Desde las lagartijas que se escabullían a lo largo del muro que construí para mantener a las serpientes letales fuera de mi jardín (no siempre funciona) hasta las aves que revolotean en los árboles autóctonos que crecen espontáneamente alrededor de mi casita en la cima de una antigua montaña. Durante la última década y media, poco a poco nos hemos asegurado mutuamente que "no nos haremos daño"; incluso la mamba5, que vive en un matorral cerca de la casa, se aleja cuando me ve (me gusta pensar en todos estos seres como mujeres... y que formamos una comunidad feminista muy especial, aunque no me hago ilusiones de que la mamba pueda matarme diez minutos después de su mordida). Me refiero a ellas en términos humanos como ba-un prefijo que humaniza en el SiSwati, 6 y a menudo [cuando así las llamo] descubro expresiones de asombro entre mis vecinos... pero solo sonrío. Sé lo que estoy

\footnotetext{
${ }^{5}$ Serpiente extremadamente venenosa.

${ }^{6}$ El suazi (siSwati en suazi) es una lengua bantú del grupo nguni hablada en Sudáfrica, Suazilandia, Lesoto y Mozambique.
} 
haciendo al reconocer el ser de los sintientes en una sociedad que se ha vuelto fría, brutal, represiva y profundamente cruel con todos los que no son hombres.

El objetivo de todo este relato es devolver la subjetividad al feminismo como un recurso crítico en la revisión de nuestras identidades y discursos políticos. Esto es algo por lo que luchamos arduamente desde el comienzo de nuestra conceptualización y teorización del feminismo como una ideología de la libertad y una herramienta política de resistencia y lucha por la integridad, por las inclusiones sociales, y en la resistencia en particular a las viciosas culturas feudales excluyentes que impregnan nuestras comunidades y vidas como mujeres africanas.

Como dijo el tan querido James Baldwin7: "El lugar en el que encajaré no existirá hasta que lo haga".

Ser mujeres completas, vibrantes y libres tiene que convertirse en un elemento central de la noción del ser africano más allá de los espacios de la ASA y la academia dentro y fuera del continente. No podemos empezar a hacer una diferencia real en la calidad y esencia de nuestras vidas como mujeres radicales a menos que nos volvamos intransigentes respecto a los derechos de todos los seres vivos a ser tratados con el mismo respeto y dignidad que exigimos. Tenemos que interrumpir y romper intencionalmente los sistemas, estructuras, mecanismos y prácticas retóricas y discursivas que se interponen entre nosotras y nuestra libertad de ser íntegras.

Los lazos que nos unen a la libertad de otros seres se forjan en los cuerpos ensangrentados y brutalizados de innumerables mujeres en los paisajes del planeta y de nuestro continente. Silvia Federici (2018) nos recuerda a través de su valiente trabajo sobre la caza de brujas y el desenfreno de la misoginia y la impunidad sexual en nuestros mundos, que el capitalismo y el feudalismo lucharon por el poder y la supervivencia en los cuerpos y en las vidas de las mujeres. La acumulación primitiva -ese descorche necesario del genio capitalista llamado fetiche- consistía inevitablemente en arrear y acorralar a las mujeres y sus capacidades reproductivas y creativas en sitios de explotación y vigilancia a instancias de los hombres de la clase dominante, de todos los colores, en las sociedades del planeta.

Como explica Federici, el advenimiento del modo de producción capitalista dependió de una misoginia viciosa y violenta, al igual que se basó en el cercamiento de la tierra, la expansión comercial, el colonialismo y la esclavitud. La misoginia ayudó a dar a luz al mundo moderno y ese mundo moderno se extendió a África mediante su incorporación al sistema imperial global del capitalismo.

Ese proyecto, iniciado a través del encuentro colonial en su "forma moderna" había comenzado hacía mucho tiempo en las sociedades del continente africano, donde las jerarquías feudales y las prácticas de explotación y la construcción cultural misógina del cuerpo femenino como sucio, peligroso y necesitado del control y la propiedad masculinos -y no confiable fuera de la mirada masculina-, sirvieron como piedras

\footnotetext{
7 James Arthur Baldwin (1924-1987), fue un novelista, ensayista, poeta, dramaturgo y activista afroestadounidense por los derechos civiles.
} 


\section{Patricia McFadden}

angulares de un sistema patriarcal que se coludió y connivió con el patriarcado blanco en el advenimiento de la incursión colonial, para establecer las sociedades neocoloniales y feudales de la época actual. Muchos se han molestado por mi insistencia en que el patriarcado es un cultivo local en todas las sociedades que sobrevivieron más allá de la etapa de "caza y recolección", y en que el patriarcado blanco simplemente reforzó las restricciones y grilletes feudales que ya ataban a las mujeres a prácticas profundamente desiguales y que a menudo les quitaban la vida en todas las sociedades africanas.

Entonces, ¿por qué tantas mujeres africanas continúan defendiendo las prácticas patriarcales feudales e incluso participan de ellas como expresión de su identidad y sentido de pertenencia a África?

¿Por qué no existe un género feminista crítico de trabajo teórico y activista sobre la noción y los sistemas del feudalismo cuando se representan y se exhiben a plena vista? Los jefes y reyes, sentados en tronos cargados por trabajadores que se humillan y se arrodillan ante estos semidioses precapitalistas. ${ }^{8} ¿$ El orgullo con el que tantos africanos declaran su estatus de "realeza" y "aristocracia" incluso cuando disfrutan del botín del saqueo y el pillaje de los recursos nacionales de nuestras sociedades? ¿Por qué nosotras, que nos llamamos feministas (y a veces como feministas radicales) hemos tenido tanto miedo de criticar la persistencia del feudalismo como el pilar de la infraestructura patriarcal que mantiene a la mayoría de las mujeres africanas esclavizadas y excluidas de los beneficios mínimos del estado neocolonial? Después de todo, las mujeres han estado exigiendo los derechos de todas las mujeres desde el encuentro inicial con el colonialismo y la intrusión racista de los colonos en nuestro continente.

¿Por qué, entonces, rehuimos la crítica necesaria del sistema patriarcal más pernicioso con el que la mayoría de nosotras nos hemos encontrado y por el que hemos sido brutalizadas -a través de las experiencias socioculturales humillantes de convertirnos en mujeres a través de la violación de nuestra integridad sexual y corporal y la odiosa mutilación genital femenina (FGM por sus siglas en inglés) y otras formas de violación sexual corporal; a través de prácticas familiares persistentes que nos excluyen y discriminan en todas las edades de nuestra vida; a través de la impunidad sexual que sustenta las crecientes tasas de feminicidio y brutalidad y odio misóginos que encontramos en la calle, en los lugares de trabajo, en las relaciones íntimas, como personas queer, como discapacitadxs y africanxs no binarios.

¿Por qué hay un silencio tan estridente sobre estas prácticas escandalosamente inaceptables que han salvaguardado el privilegio y la acumulación de riqueza de los hombres negros de la clase dominante en todo nuestro continente, mediante la colusión entre quienes están inmersos en los sistemas feudales de explotación y la extracción del ser de las mujeres y aquellos que están situados en el estado neocolonial, permitiendo uno al otro mantener un status quo brutal e inicuo?

\footnotetext{
${ }^{8}$ Aquí se refiere en particular al régimen de monarquía absoluta en su país, Eswatini.
} 
Soy consciente del montículo en nuestro camino que lxs antropólogxs blancxs y las "especialistas en género" (algunas de las cuales son negras) han colocado frente a nuestros intentos de "hablar por nosotras mismas". También soy consciente del control persistente que los financiadores y donantes tienen (dentro y fuera de la academia) sobre el contenido y la dirección del trabajo de investigación que muchas académicas feministas africanas intentan realizar. Y también soy consciente del poder que las personas que tienen control sobre los recursos -sociales, económicos, políticos y de otro tipo- pueden ejercer sobre otro ser humano, especialmente si "jugar seguro y no sacudir la jaula académica" parece ser la única opción que una tiene -estando tan lejos de un continente que cada vez ofrece menos a sus ciudadanos.

Sin embargo, hacer reverencias y obedecer sin cuestionar, nunca ha liberado a nadie. Estar en deuda con alguien porque él (como jefe de departamento de sexo masculino africano) puede detener la floreciente carrera académica de ella y convertir su vida en un infierno -de todas las formas imaginables-, solo sirve para crear una clase de personas serviles y mediocres, cuyas energías creativas y sueños son estrangulados por la falta de valor para levantarse y construir una vida digna para ella misma. Es difícil, muy difícil, mirar de frente al patriarcado y luchar contra su reacción, que a menudo es rápida y despiadada. Lo sé, y también sé que pude sobrevivir al odio misógino, a menudo sola, porque había llegado a la conciencia de que nadie puede apropiarse de mi vida, a menos que yo se lo permita. Encontrar el lugar donde puedas imaginar, crear y vivir tu feminismo contemporáneo, y aportar el valor de tu agencia radical para hacer el cambio hacia una alternativa para la humanidad, es donde está ese lugar (para hacer un riff de Nina Simone).

Desafiar y desmantelar el feudalismo es, para mí, uno de los imperativos feministas más urgentes que enfrentamos como mujeres radicales en todo nuestro continente. Tenemos que emprender un proyecto intelectual y activista para interrogar y exponer las perniciosas relaciones entre los hombres negros en el Estado y quienes ocupan las estructuras y sistemas de poder feudales, y exigir su desmantelamiento. Tenemos que exigir que la sociedad civil se extienda a todos los rincones de nuestros paisajes sociales, y que aquellos que son pagados con nuestros impuestos rindan cuentas ante nosotros como ciudadanos de nuestros países. Debemos exigir que las prácticas vergonzosas y degradantes de arrancar como malas hierbas a las personas con enfermedades mentales que son tratadas como esclavos y torturadas sean criminalizadas, y que el Estado sea responsable de esas prácticas deshumanizadoras. Tenemos que ver los vínculos entre la esclavitud de mujeres jóvenes en templos y en los hogares de hombres mayores a cambio de una miseria, como directamente relacionados con la persistencia de los sistemas feudales y el carácter fraudulento de los regímenes neocoloniales que pretenden que tal barbarie es "cultura". Sabemos que estos regímenes neocoloniales sostienen deliberadamente las infraestructuras feudales porque son un mecanismo muy efectivo para el control y vigilancia de los trabajadores, especialmente de las 


\section{Patricia McFadden}

mujeres. Mantienen la conciencia política del pueblo reprimida, haciéndolo menos amenazante para los regímenes en el poder estatal.

Sólo después de que seamos capaces de romper la relación armoniosa entre estos dos grupos de élites gobernantes, comenzaremos a responder a la brutalización generalizada de mujeres de todas las edades; a trabajar en políticas que extiendan las infraestructuras civiles, tecnológicas y materiales del Estado a todas las personas, independientemente de dónde se encuentren, y a posicionar las protecciones legales y civiles que son derechos, en las realidades vividas de todxs lxs africanxs.

El desafío que acompaña a esta propuesta es la cuestión de la identidad y nuestra relación como mujeres activistas e intelectuales con el nacionalismo y el fenómeno de la Nación. Sabemos que incluso los individuos, organizaciones y grupos feministas están vinculados -de manera profundamente íntima y visceral, con el nacionalismo y la dinámica del poder-, a los sentidos de pertenencia y autenticidad como africanxs.

Este año, Ghana está celebrando el año del regreso de nuestras hermanas y hermanos sustraídos brutalmente del continente durante un período de 400 años. La mera idea de regresar a "la patria", otra noción problemática que está vinculada a la nación, la negritud y la autenticidad, está provocando olas en las comunidades de afroamericanos de este país y conmoviendo a los africanos de la diáspora. Sí, es un tema importante que debe ser impugnado, discutido, aceptado o rechazado, como sea.

Pero esta iniciativa está sucediendo al mismo tiempo que los fundamentalistas religiosos liderados por blancos, predominantemente de ultraderecha de Estados Unidos, han ido ganando terreno en las sociedades del continente, alimentando la homofobia y el odio a las personas queer y aprovechando las oportunidades que han creado las décadas de ajuste estructural (Structural Adjustmen Programmes, SAPs por sus siglas en inglés) y de exclusión sociopolítica y económica, jugando con el cinismo y el desaliento entre la mayoría de lxs africanxs. Este ataque reaccionario va acompañado de graves retrocesos en cuanto a los derechos y la protección de las mujeres, especialmente en lo que respecta a las luchas por la integridad sexual y reproductiva, la identidad sexual y la justicia reproductiva. Han apuntado a los intentos de proporcionar a lxs jóvenes una educación sexual integral en las escuelas, y en Sudáfrica, este grupo de derecha, que está vinculado a la Conferencia Mundial de las Familias, un grupo rabiosamente conservador que también tiene vínculos con individuos dentro de la administración Trump.

Por lo tanto, soy consciente de que estoy planteando un desafío profundamente complejo y enrevesado en un contexto donde las posibilidades de rechazar las antiguas riendas feudales y construir identidades contemporáneas, personales y colectivas, parecen un sueño imposible en un lugar de encarcelamiento. Pero la vida es la fuerza más poderosa que nos otorga la naturaleza, y el instinto de libertad es nuestro derecho de nacimiento: nadie puede darnos la capacidad y la habilidad de ser libres. Es innato dentro de todas y cada una de nosotras. La forma en que 


\section{Radical y feminista: africana de otra manera}

alcanzamos y abrazamos su poder es lo que realmente es el feminismo: la capacidad y determinación para definir el arco de la propia trayectoria de vida.

Elaborar nuevas identidades más allá de las antiguas, represivas y reinventadas nociones feudales de los africanos: estas son las nuevas formas en que las podemos imaginar y articular una pertenencia inclusiva y digna.

Alejarnos de los estrechos confines del nacionalismo, que ciega y ahoga nuestras capacidades creativas, nos permitirá enriquecer nuestro feminismo desde el profundo acervo de conocimiento feminista que han aportado las mujeres de todas partes de nuestro planeta a la lucha contra el patriarcado en todas sus manifestaciones.

Imagínense cómo se verá y se sentirá nuestro feminismo cuando lo hayamos liberado de los límites intolerantes del nacionalismo como una ideología y práctica fundamentalmente anti-mujer y patriarcal. Tendremos que involucrarnos en la tarea de librarnos de las riendas del nacionalismo y sentir el viento pasar por nuestras bocas y corazones maravillosamente abiertos y alegres. Entonces no necesitamos limitar nuestra imaginación: puede correr libremente y alimentar nuestras ideas y sueños de un mundo inclusivo y suficiente. No tendremos que excluirnos unxs a otrxs como africanxs de la comunidad de humanos que, independientemente del tono de negrura que portemos, estamos unidos por siglos de resistencia y resiliencia en la lucha por recuperar nuestra humanidad del racismo, el elitismo, la explotación de clases, de todas las formas de exclusión y denigración.

Para concluir, me gustaría compartir una joya de Edward Said, cuya bella mente y corazón palestino extraño terriblemente. También echo de menos a Amilcar Cabral, por su genuino amor por los trabajadores, y su intelecto radical incisivo y profético del que he obtenido tanta inspiración y placer.

Edward señala, sobre la teoría y su centralidad en la creación y la vida de todo intelectual, y como respuesta mordaz al antiintelectualismo y la estrechez de los instintos nacionalistas:

Las personas y las escuelas críticas, las ideas y teorías viajan, de persona a
persona, de situación en situación, de un período a otro. La vida cultural e
intelectual generalmente se nutre y a menudo se sustenta en esta circulación de
ideas, ya sea que adopte la forma de una influencia reconocida o inconsciente,
un préstamo creativo o una apropiación total, el movimiento de ideas y teorías
de un lugar a otro es a la vez un hecho de vida y una condición útil de la vida
intelectual (Said, 1983, 226).

Así que les deseo a todas un presente-futuro fabulosamente radical; que sumerjan su lengua intelectual en el pozo profundo del conocimiento feminista de todas las sociedades humanas, y que hagan crecer la envergadura de sus magníficas alas feministas para que puedan volar más allá del celoso sol patriarcal y bailar con nuestra madre, la luna, y tener suficiente plenitud femenina radical. Vivan... Gracias. 
Patricia McFadden

\section{Bibliografía citada}

Federici, S. (2018). Witches, Witch-hunting, and Women. Oakland: MP Press.

Said, E. W. (1983). Traveling Theory. En E. W. Said, The World, the Text, and the Critic. Cambridge: Harvard University. 